\title{
A resiliência na tipografia digital: Interações propiciadas por programas generativos
}

\author{
Resilience in digital typography: Interactions provided by generative programs
}

\author{
Karine Itao Palos \\ Universidade Anhembi Morumbi - Brasil \\ Karineipa@hotmail.com \\ Gisela Belluzzo de Campos \\ Universidade Anhembi Morumbi - Brasil \\ giselabelluzzo@uol.com.br
}

\begin{abstract}
This article aims to describe the ephemeral qualities that typography acquires in the digital context, caused by the polyvalence of the algorithmic code, which, from generative programming, allows the user to interact with the typographic object. These reflection are realized through the study of four projects: "Lettree" (2004), "Pyrographie" (2005), "Falling in Love" (2016) and "He liked Thick Word Soup" (2014). The observations were made by drawing a comparison between the concept of "matter" in the computational scenario proposed by the design philosopher Vilém Flusser (2015) and the quality of "fluidity" observed in the images created by digital generative programs.
\end{abstract}

Keywords: Typography; Interaction; Generative Systems; Design; Resilience.

\section{Introdução}

A tipografia em ambientes totalmente digitais tem características distintas das encontradas no meio impresso ou físico - é um objeto fluido, já que seu movimento está associado ao suporte no qual se encontra. Essas características são, em parte, atribuídas a sua intangibilidade, pois só podem ser tocadas e manipuladas através de interfaces que propiciam essa mediação entre o mundo físico e o mundo algébrico.

Segundo Smeijers (1996, p.183), a evolução da computação permite a transformação da tipografia que passa de fixa no suporte físico, para móvel e ágil no suporte digital, e, deste modo, possibilita uma variedade de comportamentos.

Com isso, os objetivos deste artigo são: discutir como essa fluidez e efemeridade, presentes na tipografia digital podem, por meio do algoritmo generativo, promover a interatividade, e, entender qual o potencial da resiliência da tipografia em transparecer as mensagens por meio da interação do usuário com o caractere ou a frase, e não mais apenas pelo texto que ela abriga.

\section{Metodologia}

Os procedimentos metodológicos adotados nesta pesquisa envolvem o entendimento da conceitualização de "matéria" presente no ambiente computacional, proposto por Vilém Flusser (2015), e a discussão conceitual do que é um programa. Em uma segunda etapa, seguir-se-á relacionando o programa com os sistemas generativos no ambiente computacional. O intuito será esclarecer qual é a relação entre o código e as interações tipográficas e quais são as qualidades resilientes do tipo nesse meio. Foram escolhidos quatro projetos disponíveis na internet para essa análise, realizados tanto para o computador quanto para dispositivos móveis, são eles: "Lettree" (2004) e "Pyrographie" (2005) de Ricard Marxer Piñón; o experimento tipográfico "Falling in Love" (2016) de Daniel Kuhnlein e o aplicativo lúdico "He liked thick word soup" (2014) de Ariel Malka.

\section{Tipografia um elemento dinâmico}

A tipografia no ambiente impresso sempre esteve associada a algo estático, pois nesse meio ela adquire as características físicas do suporte, e, se materializa a partir do momento em que o pigmento se impregna na folha de papel e preenche sua forma, permanecendo imóvel e imutável até a degradação desse material ao qual foi confinada. Nas interfaces gráficas digitais, o desenho do tipo deixa sua relação com a matéria pigmento, para entrar em uma nova relação com a matéria luz. Com os formatos digitais a tipografia deixa sua existência palpável para transformar-se em bits (Esteves, 2010, p.43).

Vilém Flusser (2015) descreve esse meio físico como o mundo dos fenômenos que é uma "geleia amorfa", no qual os seres humanos experimentam por meio dos sentidos, e é o que preenche, encobre e oculta o "mundo formal" das formas eternas e imutáveis, só perceptível pela suprassensibilidade da teoria.

A materialização da tipografia é geralmente associada ao meio físico, conforme descrito acima. Segundo Flusser (2015, p.24) 
a tipografia ocorre no ambiente virtual ainda com mais propriedade, visto que a informática promove o retorno ao conceito original de "matéria" enquanto preenchimento transitório de formas temporais, entendendo-se que, segundo este autor, a forma de um objeto só existe como conceito ou sob uma perspectiva teórica.

Quando essa concepção de "matéria" é resgatada no ambiente computacional não está relacionada à fisicalidade do objeto. No computador os algoritmos ocupam a esfera teórica, eles são responsáveis pela concepção da forma que antes era restrita apenas pela cultura. Esses códigos matemáticos não só concebem a forma, como a preenche com uma infinidade de simulações de "matérias", Flusser (2011, p.218) acrescenta:

"A 'revolução da informática' surgiu, entre outras coisas, sobretudo a partir dessa reflexão que se sobrepõe ao pensar. É uma revolução porque ela inverte o ponto de partida do mundo do homem. Ela não parte mais das coisas sólidas (das moléculas), mas de partículas como elétrons e prótons, portanto, do nível do pensamento. [...] ela permite tornar visível partículas sobre as telas, computá-las ali em imagens, e, portanto, o mundo dessas partículas deve-se tornar cada vez mais interessantes" (p.218)

O algoritmo é a matéria prima para a construção do ambiente digital, ele molda e preenche todas as imagens renderizadas no computador, o que lhe confere um aspecto polivalente, que viabiliza maior intensidade nos ciclos de construção e destruição do material simulado que preenche as formas. Como se o código matemático do computador tivesse controle das moléculas e fosse capaz de fazer com que ela se transformasse de um material em outro para melhor preencher a forma.

Essa polivalência do algoritmo e do pixel permite que a tipografia não esteja fixa espacialmente e ou temporalmente ao layout (Oliveira, 2006, p.55), ou mesmo a uma forma permanente, o que significa que ela pode ser animada ou capaz de interagir com o usuário metamorfoseando-se rapidamente, por meio de comportamento especificado previamente no seu programa (Lupton, 2015, pp.165-205). Ou seja, ela passa a ser um objeto em constante transformação, dinâmico e fluido, tanto com relação às qualidades formais, quanto por meio de sua relação entre tipos e outros objetos gráficos.

A tela do computador é uma janela em que não se vê uma paisagem "real". Ela permite ver a tipografia porém, aquilo que vemos (Oliveira, 2006, p.112), é uma interface entre o mundo virtual e físico, o qual permite entrar em contato com um mundo algébrico, que traduz números em imagens ou em tipos e os preenche com materiais dos mais variados. Esse código matemático projeta formas para materializar mundos alternativos. (Flusser, 2015, p.31).

Deste modo, a tipografia materializada no digital é fluida e está em constante transformação, assim como o código que a manipula. Essas características foram observadas a seguir nos projetos: "Lettree", "Pyrographie", "Falling in Love" e "He liked Thick Word Soup".

\section{Lettree e Pyrographie}

"Lettree" de 2004 e "Pyrographie" de 2005, ambos criados por Ricard Marxer Piñón, são experimentos que propõem compartilhar conteúdos e abrir discussões sobre a caligrafia. Os dois projetos foram programados com o Processing que é uma linguagem de programação aberta, ideal para imagens, animações e áudio.

A intenção é explorar a nova dimensão da representação textual que o computador possibilita. $\mathrm{O}$ autor considera que a caligrafia pode ser utilizada como uma forma de manifestação e expressão da subjetividade humana, pois o programa permite diferentes possibilidades de representação no espaço e no tempo (Piñón, 2017).

Por meio da digitação, "Lettree" (Figura 1) permite a inserção de caracteres brancos sobre fundo negro. Cada caractere tipográfico se liga ao anterior por meio das pontas das serifas presentes em hastes, ascendentes, descendentes, pernas, caudas e remates. Dependendo das características da letra a quantidade de conexões variam. O resultado dessa interação é uma composição tipográfica que pode gerar uma infinidade de desenhos dependendo das letras que o usuário escolhe e a partir do ponto em que o programa faz a junção.

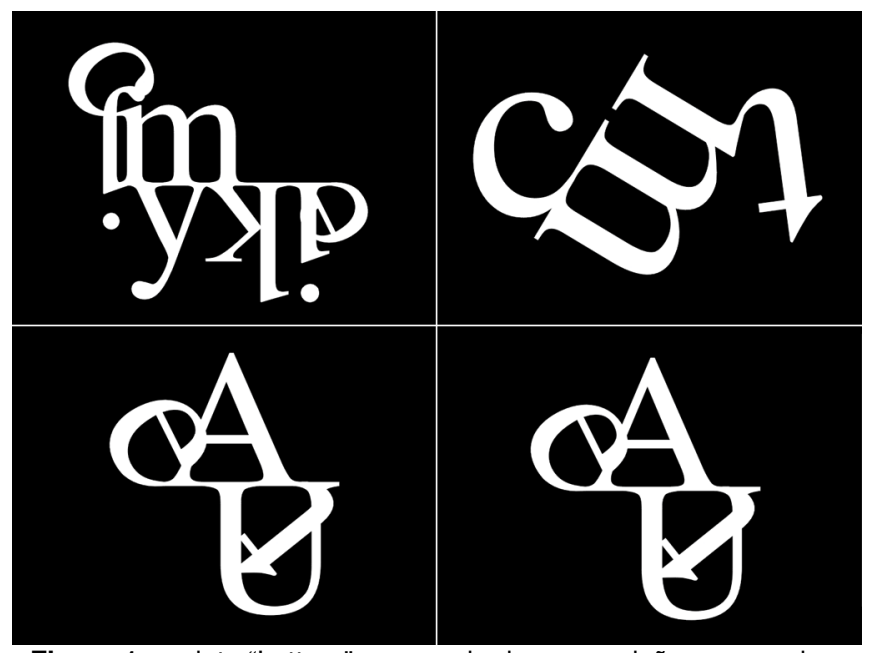

Figura 1: projeto "Lettree" - exemplo de composições que podem ser geradas pelo experimento (Piñón, 2017).

"Pyrographie" (Figura 2) é um experimento que consiste na formação de palavras por um contorno de pontos coloridos sobre fundo escuro. As palavras podem ser digitadas e são visualizadas ao teclar "enter". A interação acontece no momento que o usuário clica e arrasta o mouse. Esse movimento gera uma "comoção" nos pontos que se movem formando um rastro e, quanto mais próximos estiverem da perturbação maior é seu deslocamento. Quanto maior for à ação do usuário ao agitar o mouse, maior a distorção da tipografia e, se essa agitação for muito grande a palavra fica irreconhecível. Quando a interação cessa, os pontos voltam ao seu lugar de origem. Com um segundo "enter" os pontos, 
ao serem manuseados, podem ser arremessados para fora da tela, não retornando ao seu lugar de origem.

Esses dois projetos são concebidos para interagir no computador e constituem uma iniciativa do autor para aproximar as pessoas da tecnologia. $O$ código é utilizado para reinterpretar as letras dinamicamente, abstraindo as formas originais e permitindo com que cada experimento tenha sua própria personalidade e estilo (Richardson, 2016, p.99).

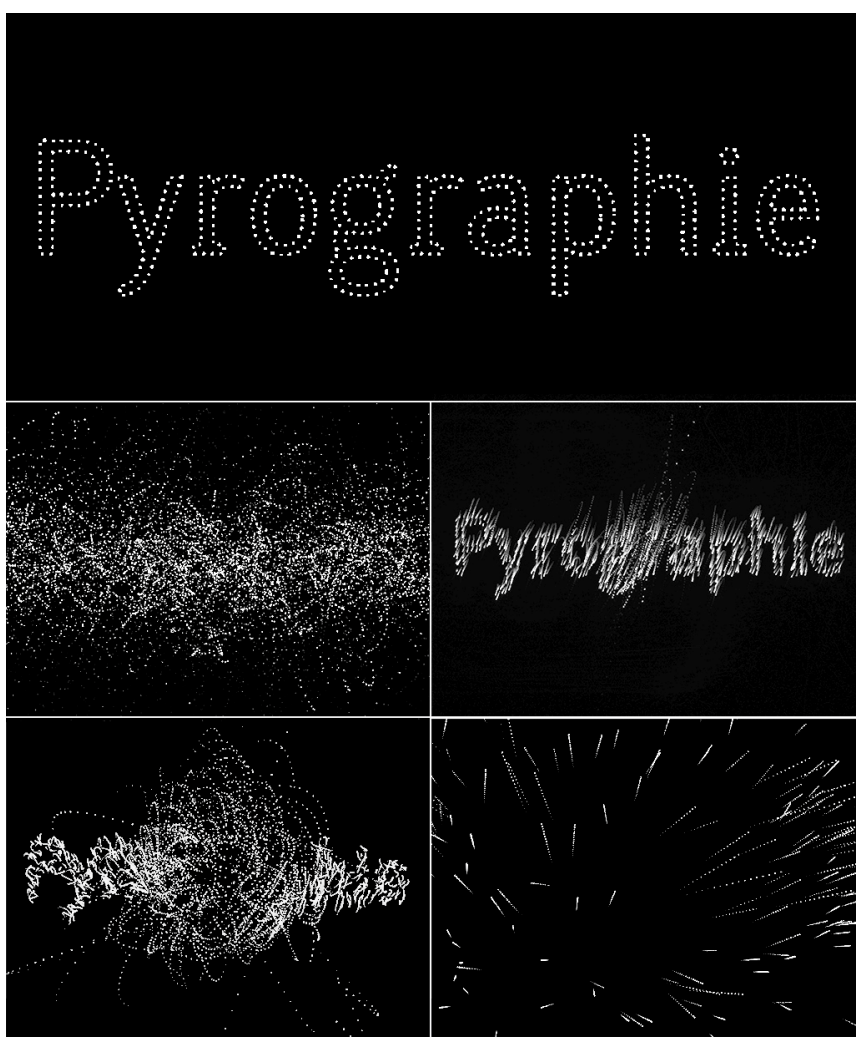

Figura 2: projeto "Pyrographie" - exemplo interferencias provocadas por interações com o emperimento (Piñón, 2017).

\section{Falling in Love}

O estúdio alemão de design standardabweichung faz experimentos baseados em tipografia que utiliza o código generativo para interagir com o usuário, dentre esses experimentos foi escolhido "Falling in Love" (ou em português "apaixonar-se") publicado em 2016, concebido pelo designer e programador Daniel Kuhnlein. Foi realizado nas linguagens HTML5 e Javascript e renderizado por meio do HTML Canvas - um conteúdo web que pode ser exibido tanto em computadores como em dispositivos móveis.

A tipografia desse experimento assemelha-se às fontes bitmap, pois todos os caracteres têm mesma largura e altura, e são construídos através de uma grade de 5X5 quadrados. Os caracteres apresentam um movimento rotativo vertical de "subida", em que apenas um é visível por vez, e a sequência se repete indefinidamente.
Em uma camada superior, o programa gera algo semelhante a uma malha formada de módulos triangulares que aderem ao formato do caractere o sobrepondo, onde se fixa por alguns segundos até que o caractere dê lugar ao próximo. Quando isso ocorre, tem-se a impressão que a malha "escorre" de uma letra para outra. O autor (Kuhnlein, 2017) explica que esse movimento é influenciado por um campo de tensão, criado via programação e que depende das coordenadas de saída e de chegada dos elementos tipográficos envolvidos. Pode também sofrer interferências do usuário por intermédio de um deslocamento do mouse ou um toque com os dedos no caso de telas touch screem. Essas perturbações resultam em um estender e contrair da malha (Figura 3).

Outra forma do usuário interagir com o experimento acontece por meio de um painel de controle, colocado no alto a esquerda da tela. Nesse painel pode-se trocar a mensagem, mudar as cores da tipografia e da malha. Esse tipo de interação, por intermédio de um painel de controle que modifica características da tipografia ou dos elementos que interagem com ela, é visto em outros projetos do estúdio, tais como: "Font Bitstream" (2016), "Font Cocon A" (2014), "The One Show: Develop your winning formula" (2016) e "Chemical Type" (2014).

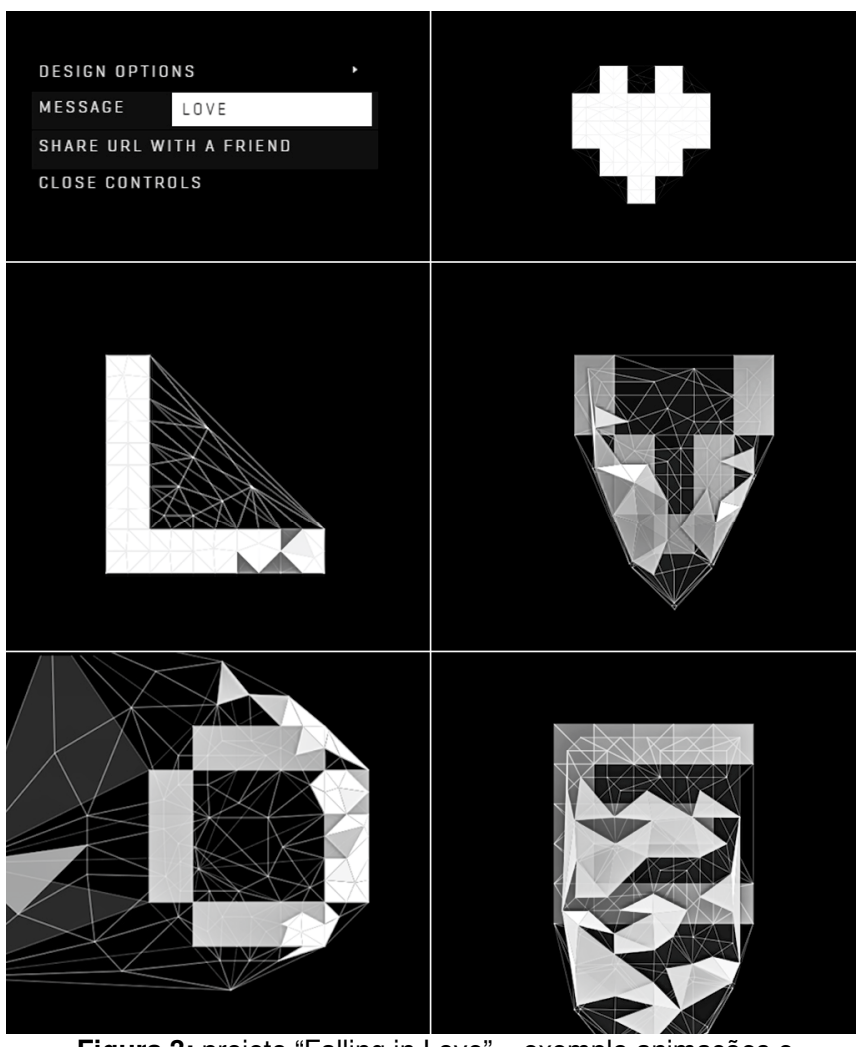

Figura 3: projeto "Falling in Love" - exemplo animações e movimento e interferencias provocadas por interações com o emperimento (Kuhnlein, 2017).

Esse experimento permite verificar a plasticidade que a tipografia tem quando passa a sofrer interferências do usuário, modificando padrões que interferem diretamente em sua anatomia como peso, contraste e espaçamento. 


\section{He liked Thick Word Soup}

O aplicativo "He liked Thick Word Soup" (ou em português "Ele gostou da Sopa grossa de palavras") publicado em 2014 foi criado por Ariel Malka, e é compatível com as plataformas Android e IOS. É um dos experimentos do projeto Chronotext, os quais o autor explora a relação entre o texto, o espaço e o tempo (Malka, 2014a).

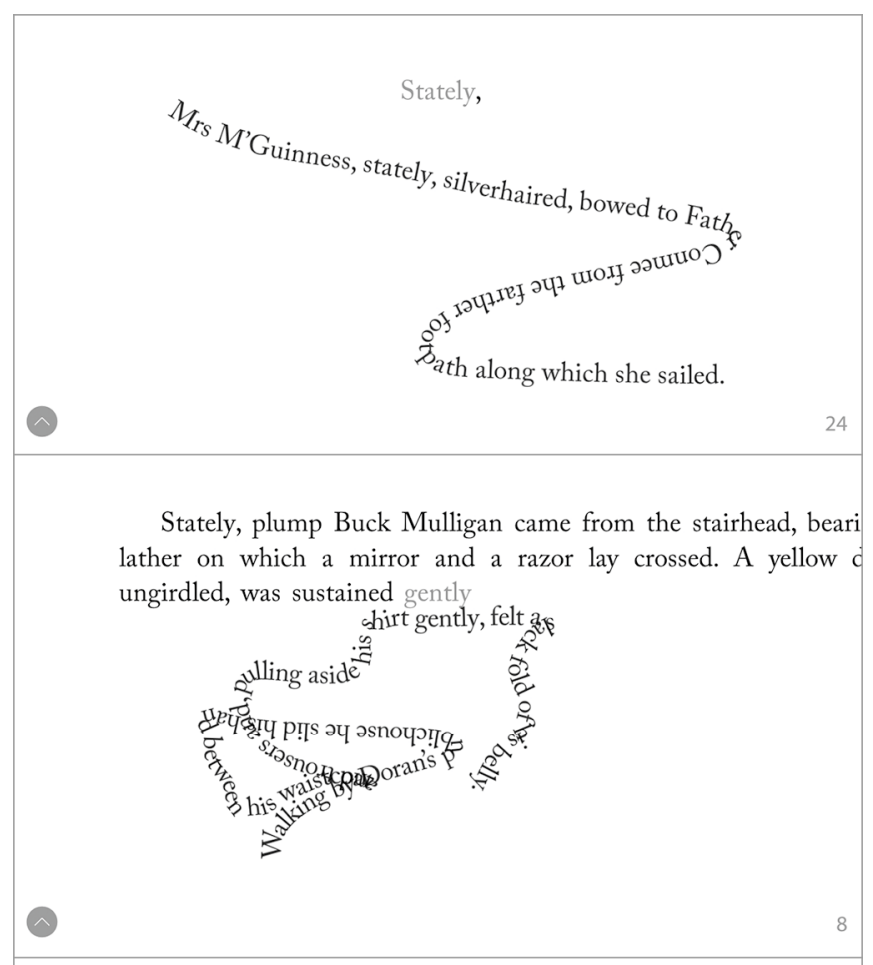

Stately, plump Buck Mulligan came from the stairhead, bearing a bow: ather on which a mirror and a razor lay crossed. A yellow dressinggo ıngirdled, was sustained gently behind him on the

Figura 4: aplicativo "He liked Thick Word Soup" - exemplo de interações e interferencias provocadas pelo usuario (Malka, 2014b).

Por meio desse aplicativo, o autor critica a busca pela maior velocidade de leitura no contexto digital. O trabalho inicia o leitor na obra Ulysses de James Joyce, publicada em 1922, considerada uma obra de difícil leitura por seu vocabulário complexo e pela quantidade de detalhes implícitos (Levin, 1960, p.94).

\section{capítulo 01: Telemachus}

gan came from the stairhead, bearing a bowl of d a razor lay crossed. A yellow dressinggown, $y$ behind him on the mild morning air.

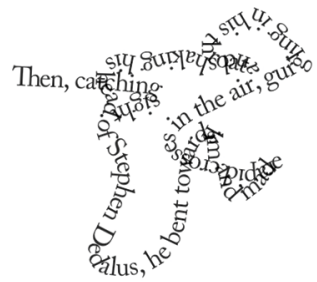

\section{capítulo 02: Nestor}

— I just wanted to say, he said. Ireland, tl being the only

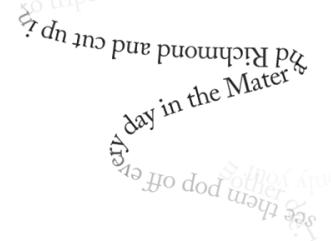

capítulo 03: Proteus

After he woke me

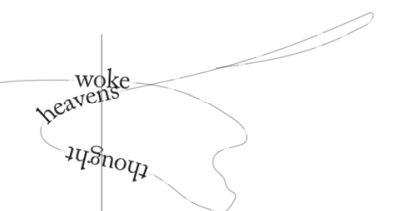

\section{capítulo 04: Calypso}

opold Bloom ate with relish the inner organs of beasts and fowls. hick giblet soup, nutty gizzards, a stuffed

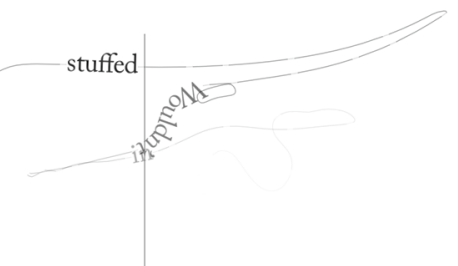

Figura 5: aplicativo "He liked Thick Word Soup" - diferença dos detalhes das interações em cada nível (Malka, 2014b).

No aplicativo são utilizados quatro fragmentos da obra de Ulysses. Cada um tem origem em um capítulo diferente, são eles: Telemachus, Nestor, Proteus e Calypso. Cada um desses fragmentos corresponde a um nível do "jogo", e são 
reconstituídos palavra por palavra mediante a interação do usuário, assemelhando-se a um quebra-cabeças em que cada "peça" é uma palavra ou um pequeno conjunto delas. As "peças" se mostram ao usuário em meio a uma sentença ou um pequeno parágrafo encontrado em outra parte do texto da obra que contenha a mesma palavra.

Assim, ao final, o usuário vai ter lido mais de cem sentenças de modo não linear. $E$, quando completar um fragmento com uma média vinte e seis "peças" ele irá desbloquear a página do livro correspondente ao trecho.

A interação com o usuário nessa obra acontece principalmente por meio dos dedos, pois os dispositivos que suportam o aplicativo têm tela touch screen. Cada sentença se comporta como um fio que pode ser puxado, esticado, enrolado ou dobrado pelo usuário, e os caracteres ficam a mercê desse movimento (isso é uma analogia com o macarrão que dialoga com o nome do aplicativo). O objetivo dessa interação é encaixar uma das palavras da sentença na palavra correspondente no fragmento (Figura 4). Ao fazê-lo a sentença é recolhida enquanto soa um áudio que simula o sorver um liquido.

É importante destacar que em cada um dos níveis um detalhe é acrescentado à interação: no primeiro, o aplicativo se comporta como o já descrito; no segundo, a sentença se esmaece gradativamente logo que o usuário para de movimentá-la; no terceiro, um fio é sempre visível e as palavras só são reveladas quando o usuário move esse fio sobre uma linha vertical no centro da tela; no quarto, além do descrito no nível anterior, a sentença também se esmaece com a falta de interação do usuário. (Figura 5)

Há ainda uma diferença entre os dispositivos, no smartphone as sentenças são reveladas uma de cada vez, no tablet as sentenças correspondentes a uma linha do fragmento são reveladas ao mesmo tempo em um único aglomerado.

O trabalho do autor é caracterizado pela criação de um ambiente que transforma as palavras em um fio de texto animado e fluido, e permite aos usuários lerem e experimentam o conteúdo de forma atrativa (Richardson, 2016, p.118). É uma forma não convencional de se trabalhar o texto e a tipografia, na qual a interatividade permite ao usuário "ler com os dedos" e desempenhar um esforço mental e físico (Malka, 2014a). Pode ser observado que tanto as interações como o áudio fornecem indícios de uma sopa.

\section{Tipografia do código generativo a interação}

Todos os projetos descritos utilizam a programação generativa para potencializar a experiência com a tipografia. A programação generativa não está associada exclusivamente ao computador, pois é uma sequencia de instruções preestabelecidas que permitem gerar um conjunto novo de combinações. Ela não limita a criação, ao contrário, a enriquece, pois o que se racionaliza são os processos, o que liberta da necessidade de tomar decisões definitivas (Gerstner, 1979, p.31).

Essas instruções podem ser interpretadas de uma variedade quase ilimitada de formas e, cada vez que a instrução é executada o resultado obtido é diferente do anterior (Omine, 2004, p.67). Para serem efetivos os programas não podem ser excessivamente rigorosos, a ponto de restringir demasiadamente a liberdade criativa, ao mesmo tempo em que não podem ser extremamente brandos, quase a serem desnecessários.

Os programas no computador também são compostos de instruções preestabelecidas. No entanto, elas são formadas por códigos matemáticos que permitem produzir trabalhos generativos de duas maneiras: a primeira, diz respeito à utilização de algoritmos randômicos que sorteiam sequências numéricas e permitem que a deformação da tipografia formada na tela seja diferente a cada vez que o programa é acionado (Gerstner, 1979, p.23; Maçãs, 2013, p.52). A segunda, permite que o computador responda a interações do usuário desencadeando ciclos de feedback, pois se o computador responde ativamente as investidas do usuário, essa resposta é percebida pelo sistema sensorial do homem que ajusta suas ações de acordo com a informação recebida (Omine, 2014, p.30).

Métodos de programação podem dividir e subdividir a estrutura formal do texto em linha ou parágrafo. As rígidas linhas de texto podem se transformar em objetos flexíveis e fluidos (Richardson, 2016, p.104). Essa característica permite que a tipografia se adapte e se autorregenere de maneira autônoma (Maçãs, 2013, pp.52-53). Esses "tipos", quando aceitam a manipulação do usuário, são caracterizados como interativos, assim como os descritos nos projetos apresentados.

\section{Discussão}

O termo resiliência - originado nas ciências duras, pode ser definido como a tendência de alguns materiais voltarem à sua forma original após terem sido deformados pela exposição à tensão ou estresse (Cerqueira, 2014, p.142). No ambiente digital resiliência pode ser descrita como a "[...] capacidade de um sistema ou uma organização de se antecipar e se adaptar a rupturas, eventos, bem como lidar com as mudanças e reconstruir seus valores e estruturas a partir destes movimentos" (Corrêa, 2015, p.09).

Os comportamentos da tipografia nos diferentes exemplos analisados configuram-se, graças aos suportes digitais, como maleáveis e dinâmicos, o que permitem caracterizá-la como resiliente.

Nos projetos descritos, pode-se perceber que a tipografia não está presa à materialidade do suporte, uma vez que o código matemático é capaz de introjetar qualquer tipo de matéria na forma. Esse código é guiado por instruções preestabelecidas, o que permite que produza objetos animados que respondam ao usuário, e assim conceda uma "nova vida" à tipografia e mais personalidade ao caractere (Richardson, 2016, p.108). 
Essas características conferem resiliência à tipografia, pois a partir da programação generativa o objeto tipográfico se torna mais autônomo, adaptando-se a perturbações ocorridas em sua estrutura ou até mesmo se regenerando ao estado inicial.

Essa interatividade com a tipografia pode acontecer de diversos modos, pois depende da forma como o algoritmo foi programado para interpretar os dados recebidos pelos inputs do usuário. Pode também prover uma resposta a essa interferência que repercute nas características intrínsecas ou extrínsecas do caractere. Esses fatos são observados em todos os projetos descritos.

"Pyrographie" e "Falling" in Love, apresentam de modo muito claro a questão da distorção interna do caractere, pois nos dois casos, com um simples arrastar do mouse tem-se os caracteres abruptamente distorcidos. O primeiro, pelos pontos no entorno do tipo que saem do seu lugar de origem, o segundo pela malha que ao ser perturbada, se expande e depois contrai.

Já em "Lettree" e em "He liked Thick Word Soup" o que está em evidência é a distorção externa da letra que engloba a relação entre os caracteres. Nos dois projetos esses caracteres se sobrepõem e têm seus espaçamentos modificados. Criam e modificam suas formas, como é descrito no primeiro caso, ou fazem alusões a objetos externos a tipografia que se materializam no próprio texto como é o caso do segundo projeto.

"[...] nós podemos mandar o computador tornar visível na tela equações opacas e por isso imagináveis (por exemplo, fractais). Nós podemos, pois, mandá-lo transformar algo totalmente abstrato em algo experienciado concretamente e por meio disso, ampliar nossa experiência com muita aventura" (Flusser, 2011, p.50-51).

Dessa forma, é evidente o potencial da tipografia no ambiente digital. Esta não fica restrita a apenas uma forma, mas é dinâmica e mutável e pode reagir instantaneamente, o que permite que os usuários possam se engajar com a interação e o movimento (Richardson, 2016, p.104). Essa característica abre um novo caminho para a experimentação tipográfica, a qual fica evidente no projeto "He liked Thick Word Soup", onde o texto e um elemento gráfico que traz a ideia da sopa.

Por fim, é importante entender como explorar melhor os recursos que a programação generativa viabiliza nos ambientes digitais interativos, que permitem que textos comportam-se como elementos gráficos "vivos" com comportamento dinâmico, pois esses podem vir a ser um artificio para atrair a atenção do usuário, em um mundo cada vez mais dominado por imagens, assim permitir a comunicação não apenas pela bagagem verbal do tipo, mas também pelo conteúdo da interação.

\section{Considerações Finais}

Percebe-se que as mídias digitais possibilitaram modificações significativas na forma como o designer trabalha com a tipografia ao permitirem a aproximação da produção e do consumo. Esta aproximação conferiu ao designer maior liberdade e facilidade no processo de criar e alterar suas próprias fontes. Essa autonomia, juntamente com a polivalência da linguagem algorítmica presente no computador, abre a possibilidade do designer desenvolver interfaces que proponham novas interações entre o leitor ou o usuário com a tipografia, essas relações extravasam o potencial do caractere tipográfico de simplesmente ser um receptáculo para o texto.

A resiliência é um fenômeno da tipografia digital, uma vez que, no meio físico, o tipo depois de impresso não consegue se descolar do suporte que lhe foi designado, não pode adaptarse a interferências externas e não tem a capacidade de retornar à sua forma original quando deformado fisicamente.

Dessa forma, as mídias digitais propiciam a exibição e a apropriação da tipografia de forma diferenciada do impresso, pois a tipografia não se encontra presa a um suporte e seu comportamento é ditado única e exclusivamente por um programa com instruções pré-estabelecidas pelo designer. Muitas vezes, o próprio desenvolvedor não tem total controle de como a tipografia vai se comportar em casos em que ela é generativa, pois ela é livre para se mover e para se adaptar, o que lhe confere resiliência. Esta realidade é muito diferente da que ocorre âmbito do impresso, onde o designer tem total controle das características formais do tipo e do posicionamento dos elementos que os rodeiam.

Constatou-se a necessidade de entender melhor como essa interação - tanto com a forma do caractere, quanto com sua relação entre os outros elementos do texto - interferem na percepção do usuário sobre os conteúdos expostos.

\section{Referências}

Cerqueira, V. M. M. (2014). Resiliência e tecnologias digitais móveis no contexto da educação básica: "senta que lá vem história". Dissertação (Mestrado em Educação) - Universidade Católica de São Paulo. São Paulo.

Corrêa, E. S. (2015). Centralidade, transversalidade e resiliência: reflexões sobre as três condições da contemporaneidade digital e a epistemologia da Comunicação. Divisão Temática Ibercom Epistemologia, Teoria e Metodologia da Comunicação no XIV Congresso Internacional IBERCOM, São Paulo, V.29, 1-15. Recuperado de http://www.scielo.br/pdf/rem/v55n3/v55n3a10.pdf

Esteves, R. (2010). O design brasileiro de tipos digitais: a configuração de um campo profissional. São Paulo, SP: Blucher.

Flusser, V. (2011). Escrita, há um futuro para a escrita?. São Paulo: Anna Brume.

Flusser, V. (2002). Filosofia da caixa preta: Ensaios para uma futura filosofia da fotografia. Rio de Janeiro: Relume Dumará.

Flusser, V. (2015). O Mundo codificado: por uma filosofia da comunicação. São Paulo: Cosac Naify.

Gerstner, K. (1979). Disenãr programas. Barcelona: Gustavo Gili. 
Kuhnlein, D. Falling in Love. (2017). Retrieved from: https://www.standardabweichung.de/design/projekte/html5/falling -love-typography-design

Levin, H. (1960). James Joyce A Critical Introduction. Nova York: WW Norton.

Lupton, E. (2015). Tipos na tela: um guia para designers, editores, tipógrafos, blogueiros e estudantes. São Paulo: Gustavo Gili.

Maçãs, C. (2013). Comportamentos da Tipografia Generativa: Uma Proposta para um Tipo Generativo. Dissertação (Mestrado em Arquitetura e Urbanismo) - Faculdade de arquitetura e urbanismo de São Paulo. São Paulo.

Malka, A. He liked thick word soup. (2014)a. Retrieved from: http://chronotext.com/WordSoup/.
Malka, A. He liked thick word soup. (2014)b. Software de computador. Android Google Play Retrieved from: http://chronotext.com/WordSoup/.

Oliveira, K. A. S. (2006). O ponto e o pixel: novas mídias novas linguagens. Dissertação (Mestrado em Design e Arquitetura) Universi dade de São Paulo. São Paulo.

Omine, E. (2014). Design gráfico computacional: comparação aplicada no projeto. Dissertação (Mestrado em Design e Multimédia) - Universidade de Ciência e Tecnologia. São Paulo.

Piñón, R. M. Caligraft. (2017). Retrieved from: http://www.caligraft.com/

Richardson, A. (2016). Data-Driven Graphic Design: Creative Coding for Visual Comunication. Londres: Bloomsbury Publishing.

Smeijers, F. (1996). Counter punch: making type in the sixteenth century, designing typefaces now. Londres: Hyphen Press. 